\title{
Correlation between UGT1A1 gene polymorphism and irinotecan chemotherapy in metastatic colorectal cancer: a study from Guangxi Zhuang
}

Shaojun Chen ${ }^{1 \dagger}$, $\mathrm{Li} \mathrm{Hua}^{1+}$, Chengjun Feng ${ }^{1+}$, Qia Mo², Mengzhuan Wei ${ }^{1}$, Yongqi Shen ${ }^{3}$, Zhan Lin ${ }^{4}$, Guisheng Li ${ }^{1}$, Junyi $\mathrm{Xu}^{5^{*}}$, Chengxian Guo ${ }^{6^{*}}$ and Haixin Huang ${ }^{1 *}$

\begin{abstract}
Background: There are obviously ethnic differences between the UGT1A1 gene polymorphisms. Due to the difference of genetic background and environment, the treatment with colorectal cancer patients of Guangxi Zhuang should not completely follow the Euramerican or Chinese han patients. The study aimed to explore the correlation of UGT1A1 gene polymorphism of Guangxi Zhuang metastatic colorectal cancer (mCRC) with irinotecan -based chemotherapy, in order to develop an individualized irinotecan regimen for mCRC patients of Guangxi Zhuang.

Methods: From June 2013 and June 2015, a total of 406 patients of Guangxi who were histologically diagnosed as metastatic colorectal cancer with 102 patients of this cohort with three generations of Zhuang, and 86 patients that conformed to inclusion and exclusion criteria were competitively enrolled. The distribution of UGT1A1 gene polymorphism was analyzed-retrospectively in all patients. Pyrosequencing method was used to detect the UGT1A $7^{*} 28$ and*6 gene polymorphism in the 86 Guangxi Zhuang mCRC patients. After first-line chemotherapy with FOLFIRI regimen, the relationship between gene polymorphism of UGTIA1 and adverse reactions, and efficacy of Irinotecan were analyzed with $\times 2$ test and Kaplan-Meier method.

(Continued on next page)
\end{abstract}

\footnotetext{
*Correspondence: twt2321@qq.com; 460873932@qq.com; huanghaixinliuzhou@126.com

'Shaojun Chen, Li Hua and Chengjun Feng contributed equally to this work. ${ }^{5}$ Department of Gastroenterological Surgery, The Fourth Affiliated Hospital of Guangxi Medical University, Liuzhou 545005, Guangxi, China

${ }^{6}$ Clinical Pharmacology Center, The Third Xiangya Hospital of Central South University, Changsha 410013, Hunan, China

'Department of Oncology, the Forth Affiliated Hospital of Guangxi Medical University, No.1 liushi Road, Liuzhou 545005, Guangxi, China

Full list of author information is available at the end of the article
}

(c) The Author(s). 2020 Open Access This article is licensed under a Creative Commons Attribution 4.0 International License, which permits use, sharing, adaptation, distribution and reproduction in any medium or format, as long as you give appropriate credit to the original author(s) and the source, provide a link to the Creative Commons licence, and indicate if changes were made. The images or other third party material in this article are included in the article's Creative Commons licence, unless indicated otherwise in a credit line to the material. If material is not included in the article's Creative Commons licence and your intended use is not permitted by statutory regulation or exceeds the permitted use, you will need to obtain permission directly from the copyright holder. To view a copy of this licence, visit http://creativecommons.org/licenses/by/4.0/ The Creative Commons Public Domain Dedication waiver (http://creativecommons.org/publicdomain/zero/1.0/) applies to the data made available in this article, unless otherwise stated in a credit line to the data. 
(Continued from previous page)

Results: UGT1A1*28 wild-type (TA6/6), heterozygous mutant (TA6/7) and homozygous mutant (TA7/7) accounted for 69.8, 30.2 and 0\%, respectively. UGT1A1*6 wild type (G/G), heterozygous mutation type (G/A) and homozygous mutant (AVA) accounted for 76.7\%, 20.9 and 2.3\%, respectively. UGT1A ${ }^{*} 28$ TA6/7 type could increase the risk of grade 3 4 diarrhea $(p=0.027)$, which did not increase the risk of grade 3 4 neutropenia $(p=0.092)$. UGT1A1*6G/A and A/A type could increase the risk of grade $3 \sim 4$ diarrhea and neutropenia ( $p=0.001 ; p=0.017)$. After chemotherapy with FOLFIRI, there was no significant difference in response rate (RR) $(p=0.729 ; p=0.745)$ or in median progression-free survival (mPFS) between the wild-type, mutant treatment of UGT1A ${ }^{*} 28$ and UGT1A ${ }^{*} 6$ (7.0 m vs $7.4 \mathrm{~m}, p=0.427 ; 6.9 \mathrm{~m}$ vs $7.0 \mathrm{~m}$ $p=0.408)$.

Conclusions: The distribution of UGT1A1*28 and UGT1A1*6 gene polymorphism in Guangxi Zhuang patients were differed from the existing reported of European people and Chinese Han population. The UGT1A1 gene polymorphism with irinotecan chemotherapy-associated diarrhea and neutropenia were closely related. There was no significant association between UGT1A1 gene polymorphism and therapeutic efficacy of irinotecan.

Keywords: Zhuang of Guangxi, UTG1A1 gene polymorphisms, Chemotherapy, Irinotecan, Metastatic colorectal cancer

\section{Background}

Colorectal cancer $(\mathrm{CRC})$ is a common gastrointestinal malignancy, with the third highest incidence and fourth highest mortality among malignant tumors worldwide $[1,2]$. Since the early symptoms of CRC are obscure, majority of the patients are diagnosed in the intermediate and late stages, and suffer from metastasis at diagnosis, with a 5 -year survival rate $<10 \%$. Chemotherapy is the main treatment method for CRC [3-5].

Irinotecan-based chemotherapy is a standard first-line or second-line regimen for the treatment of mCRC. However, irinotecan has dose-limiting toxicities, mainly neutropenia and delayed-onset diarrhea, wherein the incidence of grade 3 4 delayed-onset diarrhea and neutropenia is high. Studies have shown that UGT1A1 gene polymorphism is differently distributed among different ethnicities, which may lead to different toxicities and efficacies of irinotecan [6]. Even with the same ethnicity, the gene frequency differs in varying geographical regions [7]. Moreover, the frequency of gene mutation differs among various ethnic groups due to different genetic backgrounds. Thus, the therapeutic regimen of irinotecan should be individualized for different ethnic groups, rather than referring to the guidelines of Europe or America for Chinese Han patients. This study aimed to analyze the distribution of UGT1A1 gene polymorphisms in mCRC patients of Guangxi Zhuang, as well as the correlation of UGT1A1 gene polymorphisms with the adverse reactions and efficacy of irinotecan chemotherapy, in order to develop an individualized irinotecan regimen for $\mathrm{mCRC}$ patients of Guangxi Zhuang.

\section{Methods}

\section{Patient selection}

A total of $406 \mathrm{mCRC}$ patients receiving initial treatment in four centers of Guangxi between June 01,
2013 and June 01, 2015 were selected. After three generations of strict screening, 102 patients were found to be fully compliant with the criteria of Chinese Zhuang, of which 16 were excluded due to severe diseases and incomplete follow-up data. Eligibility criteria included: 1) Patients were diagnosed as mCRC by pathological and imaging results, and did not previously receive chemoradiotherapy; 2) Patients were Guangxi Zhuang for three generations; 3) Patients had measurable lesions by MRI or CT examination; 4) Patients had a ECOG PS $\leq 1$ point, with an expected survival of $\geq 3$ months; 5) Patients did not have significant contraindications to chemotherapy in routine blood, liver and kidney function, ECG and other examinations prior to chemotherapy; 6) Patients had no history of other malignancies; 7) Patients signed informed consent; 8) Patients were routinely followedup. The selected patients were aged 21 76 years (median age: 56 years), and their clinical data are listed in Table 1. This study was approved by the local ethics committee. Informed consent was obtained from all individual participants included in the study.

\section{Treatment regimen \\ UGT1A1 genotyping}

Genotyping studies were performed by an independent laboratory (Department of Clinical Pharmacology, Xiangya Hospital, Central South University), and $2 \mathrm{~mL}$ peripheral blood was collected in an EDTA containing glass tube about 1 week before the first chemotherapy. Subsequently, genomic DNA was extracted using the phenol-chloroform method, the target gene fragment was amplified using PCR, and the PCR products were sequenced by pyrosequencing. The UGT1A1*28 and *6 polymorphisms were read using the SNP analysis software. 
Table 1 Clinical characteristics of patients with mCRC

\begin{tabular}{lll}
\hline Variable & Number & Percentage (\%) \\
\hline $\begin{array}{lll}\text { Age (years) } \\
<60\end{array}$ & 49 & 57.0 \\
$\geq 60$ & 37 & 43.0 \\
Gender & & \\
Male & 54 & 62.8 \\
Female & 32 & 37.2 \\
PS score & & \\
0 & 29 & 33.7 \\
1 & 57 & 66.3 \\
Tumor site & & \\
Colon & 36 & 41.9 \\
Rectum & 50 & 58.1 \\
Number of metastatic sites & & \\
1 & 51 & 59.3 \\
$\geq 2$ & 35 & 40.7
\end{tabular}

\section{Chemotherapy regimen}

The selected patients received a first-line chemotherapy with irinotecan $(\mathrm{CPT}-11)+5$-Fluorouracil $(5-\mathrm{Fu}) /$ LV (FOLFIRI) regimen. The dosage and administration were as follows: patients were given intravenous infusion of irinotecan $(180 \mathrm{mg} / \mathrm{m} 2,90 \mathrm{mins}), \mathrm{d} 1$,intravenous infusion of $\mathrm{LV}(400 \mathrm{mg} / \mathrm{m} 2), \mathrm{d} 1$, and intravenous injection of $5-\mathrm{Fu}(400 \mathrm{mg} / \mathrm{m} 2), \mathrm{d} 1$. Then, the patients were given continuous intravenous injection of 5 -Fu $(2400 \mathrm{mg} / \mathrm{m} 2), 46 \sim 48 \mathrm{~h}$. All the treatment were repeated every 2 weeks for $4 \sim 6$ cycles. The efficacy was evaluated after patients were given at least four cycles of treatment.

\section{Response and toxicity evaluation}

The follow-up ranged from 31 55 months with a median 40 months as of Jan 2018. Four cases were lost to follow-up, with a follow-up rate of $95.56 \%$. The primary endpoint of this study was toxicity, and the secondary endpoint included short-term efficacy and progression-free survival (PFS). The efficacy was evaluated according to the response evaluation criteria in solid tumors, Revised RECIST guidelines (version 1.1) [8]. The adverse reactions were evaluated according to the evaluation and classification of neutropenia, delayed diarrhea in National Cancer Institute NCI-CTC (version 3.0) [9].

\section{Endpoints and statistical analysis}

All SNPs were analyzed for deviation from HardyWeinberg equilibrium (HWE), and the genotype and allelic frequencies were calculated. Two-tailed Fisher's exact test was used to calculate the genotype distribution in controls and patients, and to compare the differences between both groups; $\chi^{2}$ test or Fisher exact probability was used to analyze the adverse reactions and efficacy. Logistic regression was adopted to analyze the relationship between the clinical characteristics of patients and the adverse reactions of irinotecan. Kaplan-Meier method was used to plot the survival curve as well as analyze the relationship between different genotypes and PFS.

\section{Results}

\section{Distribution of the UGT1A1 genotype}

The genotype distribution of UGT1A1 gene*28 and *6 in 86 patients was consistent with the HardyWeinberg equilibrium (HWE) $(p>0.1)$ in population genetics, as shown in Table 2. For the UGT1A1*28, there were 60 cases (69.8\%) of wild-type (TA6/6), 26 cases $(30.2 \%)$ of heterozygous-type (TA6/7), and no case of homozygous-type (TA7/7). The sequencing results are shown in Fig. 1 . For the $U G T 1 A 1 * 6$, there were 66 cases $(76.7 \%)$ of wild-type (G/G), 18 cases (20.9\%) of heterozygous-type (G/A) and two cases (2.3\%) of homozygous-type (A/A). The sequencing results are shown in Fig. 2.

Toxicity to chemotherapy based on the UGT1A1 genotype Among the 86 patients, there were 60 cases of UGT1A1*28 TA6/6, of which seven cases (11.7\%) experienced grade 3 4 delayed-onset diarrhea and nine cases $(15.0 \%)$ had grade $3 \sim 4$ neutropenia. Among the 26 cases of UGT1A1*28 TA6/7, nine cases (34.6\%) experienced grade 3 4 delayed-onset diarrhea and eight cases (30.8\%) had grade 3 4 neutropenia. Statistical analysis revealed that $U G T 1 A 1^{*} 28$ TA6/7 patients had a higher risk of grade $3 \sim 4$ delayed-onset diarrhea as compared to UGT1A1*28 TA6/6 patients, and the difference was statistically significant $\left(\mathrm{X}^{2}=\right.$ 4.884, $p=0.027)$. Meanwhile, UGT1A1*28 TA6/7 was unlikely to increase the risk of grade $3 \sim 4$

Table 2 Distribution of UGT1A1 genotype in Guangxi Zhuang

\begin{tabular}{llll}
\hline Variable & Number (\%) & Allelic & H-W equilibrium p \\
& & frequencies & \\
\hline UGT1A1*28 & & & \\
Wild TA6/6 & $60(69.8)$ & TA6 0.849 & \\
Heterozygous TA6/7 & $26(30.2)$ & TA7 0.151 & \\
Homozygous TA7/7 & $0(0)$ & & 0.834 \\
UGT1A1*6 & & & \\
Wild (G/G) & $66(76.7)$ & G 0.872 & \\
Heterozygous (G/A) & $18(20.9)$ & A 0.128 & \\
Homozygous (A/A) & $2(2.3)$ & & \\
\hline
\end{tabular}




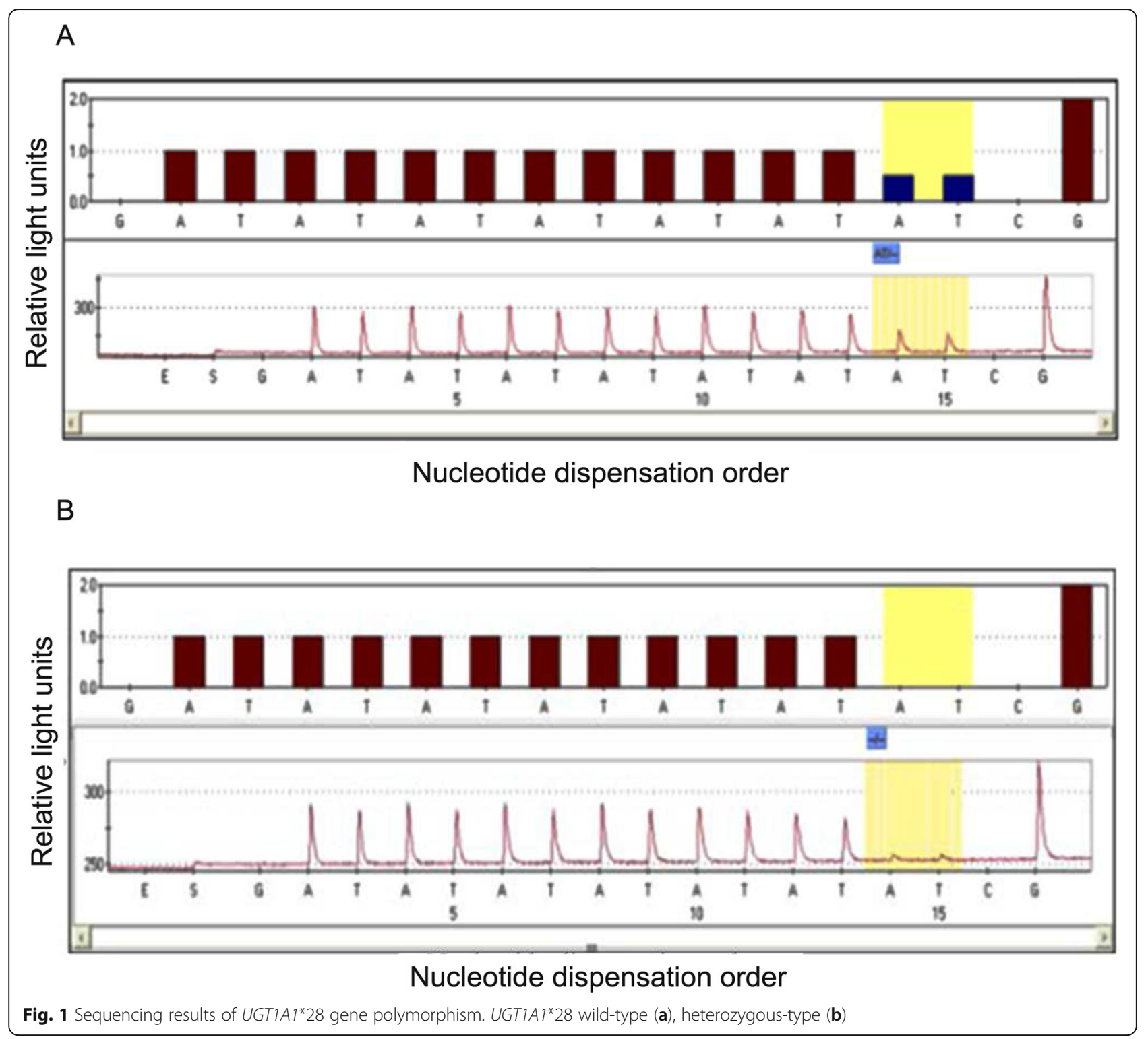

neutropenia $\left(\chi^{2}=2.844, p=0.092\right)$. Among the 86 patients, there were 66 cases of $U G T 1 A 1 * 6 \mathrm{G} / \mathrm{G}$, of which six cases (9.1\%) experienced grade 3 4 delayed-onset diarrhea, and 10 cases (15.2\%) had grade $3 \sim 4$ neutropenia. Among the 20 cases of UGT1A1*6 G/A + A/A, nine cases (45.0\%) had grade 3 4 delayed-onset diarrhea and eight cases (40.0\%) experienced grade $3 \sim 4$ neutropenia. Statistical analysis showed that $U G T 1 A 1^{*} 6 \mathrm{G} / \mathrm{A}+\mathrm{A} / \mathrm{A}$ patients had a higher risk of grade $3 \sim 4$ diarrhea as compared to G/G patients, with statistically significant difference $\left(\chi^{2}=11.364, p=0.001\right)$, and also a higher risk of grade 3 4 neutropenia as compared to G/G patients $\left(\chi^{2}=5.727, p=0.017\right)$. In this study, no patient suffered from adverse event-related death. (Table 3).
The delayed diarrhea and neutropenia was not associated with gender, age, PS score, primary lesion and the number of metastatic organs $(p>0.05)$ (Table 4$)$, but associated with genotype((Table 5, Fig. 3; Table 6, Fig. 4). The probability of occurrence of grade $3 \sim 4$ delayed diarrhea and neutropenia in wild-type patients was significantly lower than that in singlepoint and double-point mutants $\left(\chi^{2}=8.802, p=\right.$ $\left.0.005, \chi^{2}=23.171, p=0.000\right)$. (Tables 7 and 8 ).

Response to chemotherapy based on the UGT1A1 genotype

Among the $86 U G T 1 A 1 * 28$ patients, there were two cases of CR (7.7\%) (both of TA6/7), 32 cases of PR [including 23 TA6/6 cases (38.3\%) and nine TA6/7 cases 


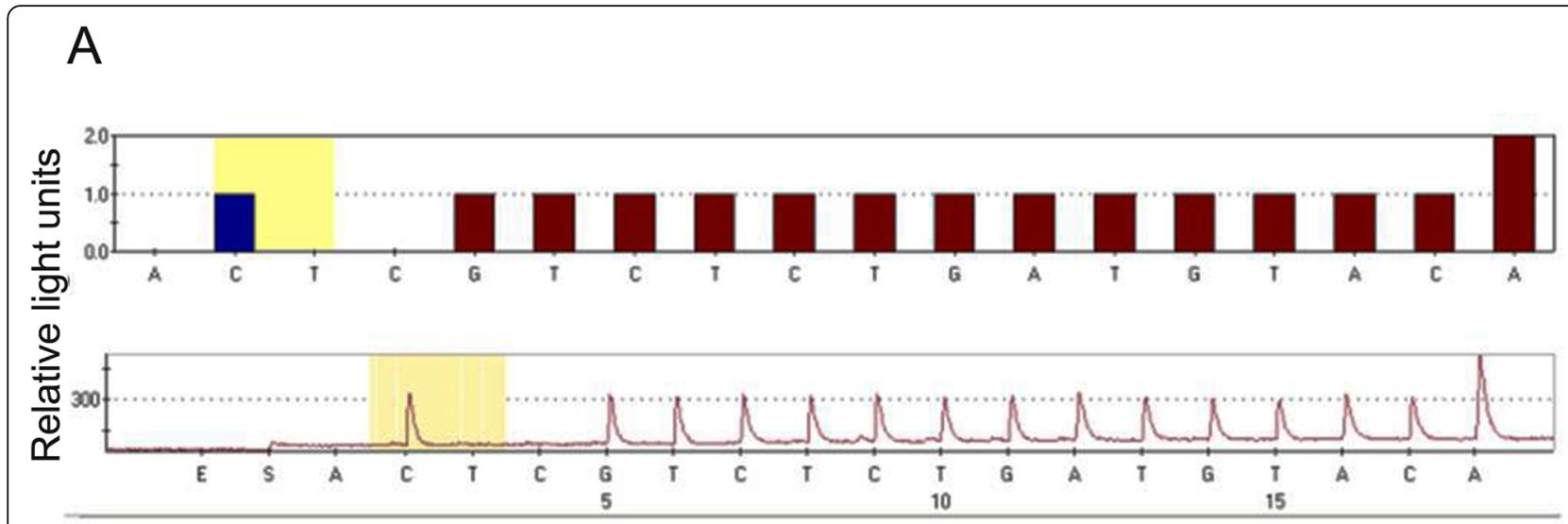

Nucleotide dispensation order

B

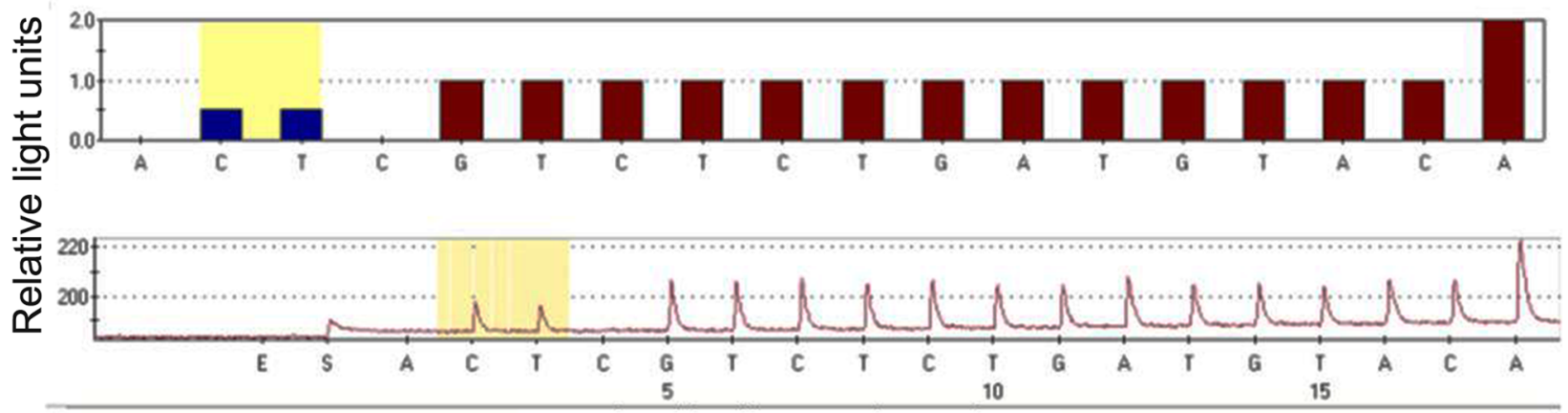

Nucleotide dispensation order

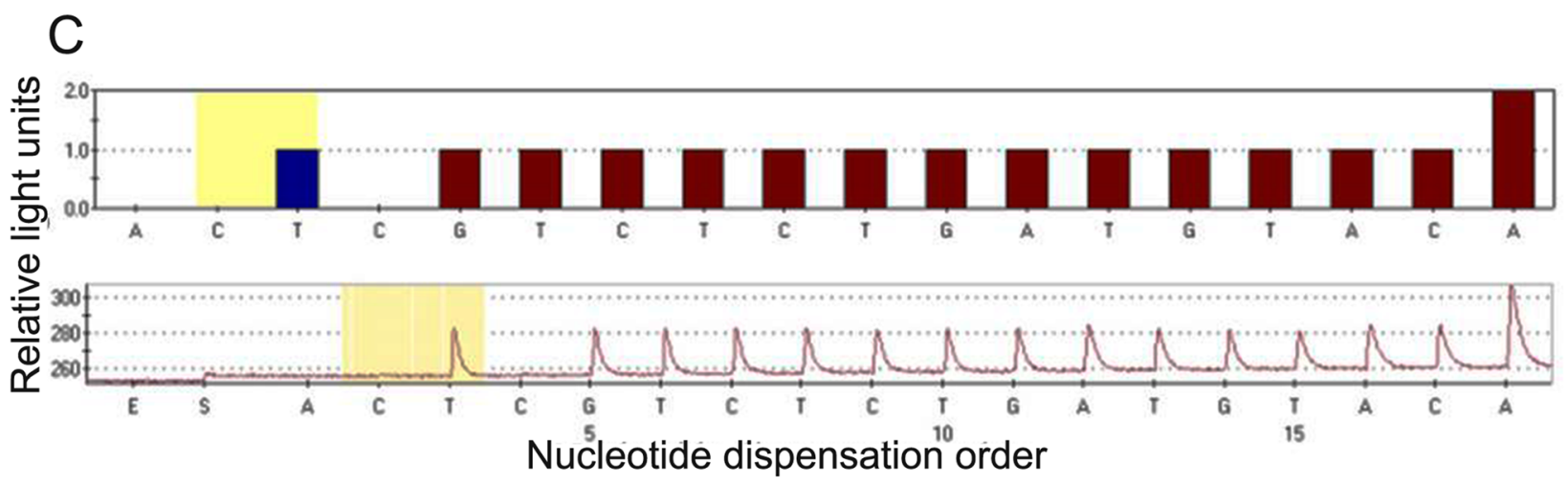

Fig. 2 Sequencing results of UGT1A1*6 gene polymorphism. UGT1A1*6 wild-type (a), heterozygous-type (b), homozygous-type (c)

(34.6\%)], 30 cases of SD [including 21 TA6/6 cases (35.0\%) and nine TA6/7 cases (34.6\%)], and 22 cases of PD [including 16 TA6/6 cases (26.7\%) and six TA6/7 cases (23.1\%)] (Fig. 5). Among the $86 U G T 1 A 1^{* 6}$ patients, there were two cases of CR [one G/G case (1.5\%) and one $\mathrm{G} / \mathrm{A}+\mathrm{A} / \mathrm{A}$ case (5.0\%)], 34 cases of PR [including $26 \mathrm{G} / \mathrm{G}$ cases (39.4\%) and eight $\mathrm{G} / \mathrm{A}+\mathrm{A} / \mathrm{A}$ cases (40.0\%)], 28 cases of SD [including $22 \mathrm{G} / \mathrm{G}$ cases $(33.3 \%)$ and six $\mathrm{G} / \mathrm{A}+\mathrm{A} / \mathrm{A}$ cases $(30 \%)]$, and 22 cases of PD [including $17 \mathrm{G} / \mathrm{G}$ cases (25.8\%) and five $\mathrm{G} / \mathrm{A}+\mathrm{A} / \mathrm{A}$ cases (25\%)] (Tables 4 and 5). Of these, the ORRs of UGT1A1*28 TA6/6 and TA6/7 patients after chemotherapy were 38.3 and $42.3 \%\left(\chi^{2}=0.120, p=0.729\right)$, respectively, while those of UGT1A1*6 G/G and G/A + A/ A patients were 40.9 and $45.0 \%\left(\chi^{2}=0.106, p=0.745\right)$, respectively. (Tables 9 and 10). 
Table 3 Toxicity and UGT1A1 status (\%)

\begin{tabular}{|c|c|c|c|c|c|c|}
\hline \multirow[t]{2}{*}{ Toxicity } & \multicolumn{2}{|c|}{ UGT1A $1 * 28$} & \multirow[t]{2}{*}{ P } & \multicolumn{2}{|c|}{ UGT1A1*6 } & \multirow[t]{2}{*}{$P$} \\
\hline & $\begin{array}{l}\text { TA6/6 } \\
\text { Number } \\
(\%)\end{array}$ & $\begin{array}{l}\text { TA6/7 } \\
\text { Number } \\
(\%)\end{array}$ & & $\begin{array}{l}\text { G/G } \\
\text { Number } \\
(\%)\end{array}$ & $\begin{array}{l}\mathrm{G} / \mathrm{A}+\mathrm{A} / \mathrm{A} \\
\text { Number } \\
(\%)\end{array}$ & \\
\hline \multicolumn{7}{|l|}{ Diarrhea } \\
\hline 0 grade & $41(68.3)$ & $10(38.5)$ & 0.027 & $45(68.2)$ & $7(35.0)$ & 0.001 \\
\hline $1-2$ grade & $12(20.0)$ & $7(26.9)$ & & 15 (22.7) & $4(20.0)$ & \\
\hline $3-4$ grade & $7(11.7)$ & $9(34.6)$ & & $6(9.1)$ & $9(45.0)$ & \\
\hline \multicolumn{7}{|l|}{ Neutropenia } \\
\hline 0 grade & $33(55.0)$ & $10(38.4)$ & 0.092 & 38 (57.6) & $5(25.0)$ & 0.017 \\
\hline $1-2$ grade & $18(30.0)$ & $8(30.8)$ & & 18 (27.3) & $7(35.0)$ & \\
\hline $3-4$ grade & $9(15.0)$ & $8(30.8)$ & & 10 (15.2) & $8(40.0)$ & \\
\hline
\end{tabular}

Progression-free survival based on the UGT1A1 genotype Patients were followed-up until June 01, 2017. The median PFS of UGT1A1*28 TA6/6 and TA6/7 patients were 7.0 and 7.4 months, respectively, with statistically insignificant difference $(p=0.427)$, and those of $U G T 1 A 1^{*} 6 \mathrm{G} / \mathrm{G}$ and $\mathrm{G} / \mathrm{A}+\mathrm{A} / \mathrm{A}$ patients were 6.9 and 7.0 months, respectively, with statistically insignificant difference $(p=0.408)$. The survival curves plotted using the Kaplan-Meier method are shown in Figs. 6 and 7.

\section{Distribution of the UGT1A1 genotype with irinotecan dose reduction}

Among the 86 patients, irinotecan dose was reduced in 15 patients, including six cases of wild-type (TA6/6)

Table 4 Toxicity and clinical characteristics

\begin{tabular}{|c|c|c|c|c|c|c|c|c|}
\hline \multirow{2}{*}{$\begin{array}{l}\text { Clinical } \\
\text { feature }\end{array}$} & \multicolumn{3}{|c|}{ Diarrhea } & \multirow[t]{2}{*}{$P$} & \multicolumn{3}{|c|}{ Neutropenia } & \multirow[t]{2}{*}{$P$} \\
\hline & $\begin{array}{l}0 \\
\text { grade }\end{array}$ & $\begin{array}{l}1-2 \\
\text { grade }\end{array}$ & $\begin{array}{l}3-4 \\
\text { grade }\end{array}$ & & $\begin{array}{l}0 \\
\text { grade }\end{array}$ & $\begin{array}{l}1-2 \\
\text { grade }\end{array}$ & $\begin{array}{l}3-4 \\
\text { grade }\end{array}$ & \\
\hline \multicolumn{9}{|l|}{ Age (years) } \\
\hline$<60$ & 31 & 12 & 6 & 0.332 & 28 & 11 & 10 & 0.235 \\
\hline$\geq 60$ & 21 & 7 & 9 & & 15 & 14 & 8 & \\
\hline \multicolumn{9}{|l|}{ Gender } \\
\hline Male & 32 & 12 & 10 & 0.936 & 27 & 15 & 12 & 0.905 \\
\hline Female & 20 & 7 & 5 & & 16 & 10 & 6 & \\
\hline \multicolumn{9}{|l|}{ PS score } \\
\hline 0 & 17 & 7 & 5 & 0.947 & 13 & 9 & 7 & 0.776 \\
\hline 1 & 35 & 12 & 10 & & 30 & 16 & 11 & \\
\hline \multicolumn{9}{|l|}{ Tumor site } \\
\hline Colon & 23 & 8 & 5 & 0.753 & 18 & 11 & 7 & 0.945 \\
\hline Rectum & 29 & 11 & 10 & & 25 & 14 & 11 & \\
\hline \multicolumn{9}{|c|}{$\mathrm{N}$ of metastatic organs } \\
\hline 1 & 31 & 12 & 8 & 0.843 & 25 & 15 & 11 & 0.974 \\
\hline 2 & 21 & 7 & 7 & & 18 & 10 & 7 & \\
\hline
\end{tabular}

Table 5 Multivariate analysis ofthe logistic risk ratio model for Delayed diarrhea

\begin{tabular}{|c|c|c|c|c|c|}
\hline \multirow[t]{2}{*}{ Delayed diarrhea } & \multirow[t]{2}{*}{$\beta$} & \multirow[t]{2}{*}{ Sig } & \multirow[t]{2}{*}{$\operatorname{Exp}(B)$} & \multicolumn{2}{|l|}{$95 \% \mathrm{Cl}$} \\
\hline & & & & $\begin{array}{l}\text { Lower } \\
\text { Bound }\end{array}$ & $\begin{array}{l}\text { Upper } \\
\text { Bound }\end{array}$ \\
\hline Age & 0.749 & 0.287 & 2.115 & 0.533 & 8.386 \\
\hline Sex & -0.679 & 0.381 & 0.507 & 0.111 & 2.386 \\
\hline PS scores & -0.364 & 0.643 & 0.695 & 0.149 & 3.242 \\
\hline Primary origin & 0.294 & 0.700 & 1.341 & 0.301 & 5.982 \\
\hline $\begin{array}{l}\text { Number of organs } \\
\text { with metastases }\end{array}$ & 0.736 & 0.317 & 2.089 & 0.493 & 8.844 \\
\hline genotypa & 1.904 & 0.000 & 6.710 & 2.504 & 17.978 \\
\hline constant & -5.337 & 0.000 & 0.005 & & \\
\hline
\end{tabular}

and nine cases of mutant-type (TA6/7) UGT1A1*28, and seven cases of wild-type $(\mathrm{G} / \mathrm{G})$ and eight cases of mutant-type (G/A) UGT1A1*6. This indicated that a higher ratio of patients with mutant-type UGT1A1*28 and $U G T 1 A 1 * 6$ required irinotecan dose reduction as compared to patients with wild-type UGT1A1*28 and UGT1A1*6 ( $\left.\mathrm{x}^{2}=6.019, p=0.014 ; \mathrm{x}^{2}=7.281, p=0.007\right)$ (Table 11). During subsequent chemotherapy, the irinotecan dose was reduced by about $20 \%$. Fifteen patients could tolerate the reduced dose of irinotecan, and did not require irinotecan dose reduction to the next gradient.

\section{Toxicity of irinotecan dose reduction based on the UGT1A1 genotype}

After the irinotecan dose was reduced, the incidences of grade 3 4 diarrhea and grade 3 4 neutropenia were significantly decreased in both the dose reduction group and non-dose reduction group for patients with UGT1A1*28 ( $p=1.000 ; p=0.613)$ and UGT1A1*6 $(p=0.442 ; p=0.139)$ in Table 12 .

\section{Efficacy of irinotecan dose reduction based on the UGT1A1 genotype}

In patients with UGT1A1*28 and UGT1A1*6 genes, there was insignificant difference in the short-term effect between the dose reduction group and non-dose reduction group $(p=0.402, p=0.368)$ (Figs. 8 and 9). Also, there was insignificant difference in the median PFS between the dose reduction group and non-dose reduction group ( $2=1.946, p=0.378 ; \mathrm{X}^{2}=1.895, p=$ 0.388) (Table 13).

\section{Discussion}

Irinotecan is a semi-synthetic derivative of natural camptothecin, and has been widely used in the treatment of solid tumors such as gastric cancer, colorectal cancer (CRC), lung cancer, etc. A combination of 


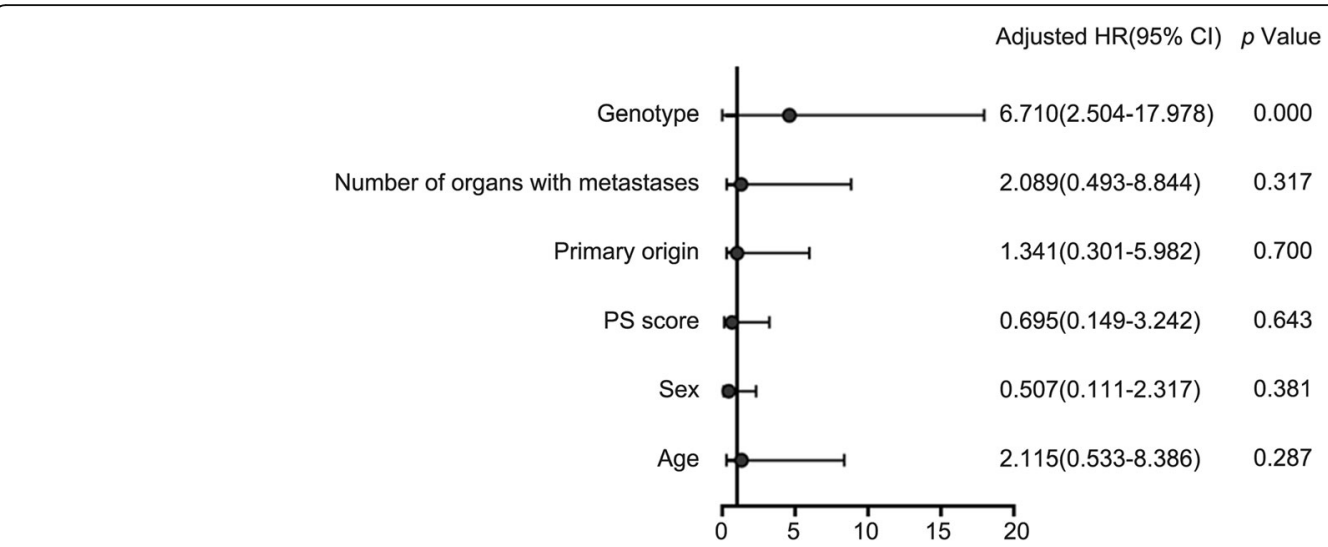

Fig. 3 Multiple factors analysis of delayed diarrhea by Logistic regression

irinotecan and fluorouracil is a standard first-line regimen for advanced CRC, especially advanced CRC with rapid progression, with an efficacy rate of up to $40 \%$ [10-12]. However, this regimen has two major adverse reactions of delayed-onset diarrhea and neutropenia, where the incidences of grade 3 4 neutropenia and severe diarrhea are $45 \%$ and $20 \sim 40 \%$ [13], respectively, which limits its clinical application and exhibits inter-individual variations.

Irinotecan is hydrolyzed in vivo by carboxylesterase (CE) into an active metabolite 7-ethyl-10-hydroxycamptothecin (SN-38). The latter is a topoisomerase I inhibitor that inhibits repair of broken singlestranded DNA, disrupts DNA replication and transcription, and exerts cytotoxic effects. SN-38 is inactivated by UGT1A1 as glucuronic acid product $\mathrm{SN}-38 \mathrm{G}$, which is excreted into the intestine through the bile and is transformed into $\mathrm{SN}-38$ by the intestinal bacterial $\beta$-glucuronidase, thereby inducing mucosal injury and delayed-onset diarrhea. UGT1A1 enzyme in the intestine can re-catalyze $\mathrm{SN}-38$ for SN-38G detoxification. Therefore, the adverse

Table 6 Multivariate analysis of logistic risk ratio model for neutropenia

\begin{tabular}{llllll}
\hline neutropenia & $\beta$ & $\operatorname{Sig}$ & $\operatorname{Exp}(\mathrm{B})$ & \multicolumn{2}{l}{$95 \% \mathrm{Cl}$} \\
\cline { 5 - 7 } & & & & Lower Bound & Upper Bound \\
\hline Age & -0.107 & 0.869 & 0.899 & 0.253 & 3.194 \\
Sex & -0.495 & 0.473 & 0.610 & 0.158 & 2.353 \\
PS scores & -0.574 & 0.421 & 0.563 & 0.139 & 2.281 \\
Primary origin & 0.430 & 0.530 & 1.537 & 0.402 & 5.879 \\
Number of organs & 0.428 & 0.527 & 1.534 & 0.408 & 5.770 \\
with metastases & & & & & \\
genotypa & 1.898 & 0.000 & 6.671 & 2.708 & 16.434 \\
constant & -4.362 & 0.000 & 0.013 & & \\
\hline
\end{tabular}

reactions of irinotecan are related to its main drugmetabolizing enzyme UGT1A1, whose activity is affected by polymorphism. UGT1A1*28 polymorphism and irinotecan-related adverse reactions have been reported in many studies, but the correlation between UGT1A1*6 polymorphism and adverse reactions of irinotecan remains unclear. Several studies, with conflicting results, have indicated that the UGT1A1 polymorphism has insufficient sensitivity and specificity in predicting the adverse effects of irinotecan. The results of different ethnic groups in the same race are rarely reported. In addition, the role of UGT1A1 polymorphism in predicting the toxicity in patients receiving different doses of irinotecan is clinically controversial.

Due to differences in genetic background, different UGT1A1 mutation sites exist among various ethnic groups, which is responsible for different incidences of toxicity between different populations in eastern

Table 7 Delayed diarrheacompared withUGT1A1wildtype、 single-point and double-point mutants (\%)

\begin{tabular}{|c|c|c|c|c|c|}
\hline \multirow{2}{*}{$\begin{array}{l}\text { Genotype } \\
\text { UGT1A1*28 }\end{array}$} & \multirow{2}{*}{$\begin{array}{l}\text { Total } \\
n\end{array}$} & \multicolumn{2}{|c|}{ Delayed diarrhea n(\%) } & \multirow{2}{*}{$\begin{array}{l}X^{2} \\
6.308\end{array}$} & \multirow{2}{*}{$\begin{array}{l}P \\
0.017\end{array}$} \\
\hline & & $\overline{0 \sim \|}$ & $|I I \sim| V$ & & \\
\hline$\overline{6 / 6}$ & 60 & $53(88.3)$ & $7(11.7)$ & & \\
\hline $6 / 7$ & 26 & $17(65.4)$ & $9(34.6)$ & & \\
\hline UGT1A1*6 & & & & 13.745 & 0.001 \\
\hline $\mathrm{G} / \mathrm{G}$ & 66 & $60(90.9)$ & $6(10.0)$ & & \\
\hline $\mathrm{G} / \mathrm{A}+\mathrm{A} / \mathrm{A}$ & 20 & $11(55.0)$ & $9(24.3)$ & & \\
\hline $\begin{array}{l}\text { Numbers of mutational } \\
\text { alleles }\end{array}$ & & & & 8.802 & 0.005 \\
\hline Double single type & 53 & $50(94.3)$ & $3(5.7)$ & & \\
\hline Single variant & 22 & 17(77.3) & $5(22.7)$ & & \\
\hline Double variant & 11 & 7 (63.6) & $4(36.3)$ & & \\
\hline
\end{tabular}




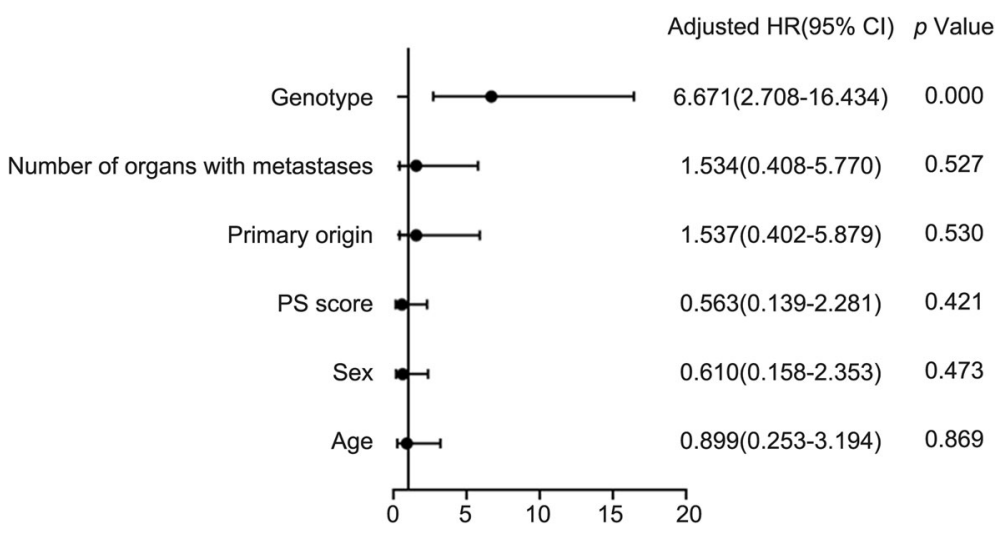

Fig. 4 Multiple factors analysis of neutropenia by Logistic regression

and western countries receiving irinotecan treatment. Studies on the distribution of UGT1A1"28 and *6 polymorphisms have demonstrated that UGT1A1 * 28 homozygous mutant TA7/7 accounts for 10 15\% and $12 \sim 27 \%$ in the Caucasian and African populations, respectively $[14,15]$, while its mutation rate is only $1.2 \sim 4.7 \%$ in Asian population $[16,17]$. Nakaura et al. [18] showed that the wild-type UGT1A1*28 accounted for 46 and $76 \%$ in the Caucasian and Asian populations, respectively, indicating significant inter-ethnic differences. Etienne-Grimald et al. [19] concluded that UGT1A1*28 had the highest expression frequency in Americans and Caucasians, accounting for $38 \sim 45 \%$ and $29 \sim 39 \%$, respectively, while a mutation frequency of about $15 \sim 18 \%$ in Asians, of which the homozygous mutation type accounted for $3 \%$. Zhang et al. [20] investigated the distribution of UGT1A1*28 polymorphism in 517 Han patients, and found that UGT1A1*28 TA6/6, TA7/6 and TA7/7

Table 8 Neutropenia compared withUGT1A1 wild-type、 singlepoint and double-point mutants (\%)

\begin{tabular}{lllllll}
\hline Genotype & Total & \multicolumn{2}{l}{ neutropenia $n(\%)$} & $X^{2}$ & $P$ \\
UGT1A1*28 & $n$ & $0 \sim 11$ & II IV & 2.844 & 0.139 \\
\hline $6 / 6$ & 60 & $51(85.0)$ & $9(15.0)$ & & \\
$6 / 7$ & 26 & $18(69.2)$ & $8(30.8)$ & & \\
UGT1A1*6 & & & & 5.727 & 0.027 \\
G/G & 66 & $56(84.8)$ & $10(15.2)$ & & \\
G/A + A/A & 20 & $12(60.0)$ & $8(40.0)$ & & \\
Numbers of mutational & & & & 23.171 & 0.000 \\
alleles & & & & & \\
Double single type & 53 & $50(94.3)$ & $3(5.7)$ & & \\
Single variant & 22 & $13(59.1)$ & $9(40.9)$ & & \\
Double variant & 11 & $4(36.4)$ & $7(63.6)$ & & \\
\hline
\end{tabular}

accounted for $77.2,22$ and $0.8 \%$, respectively. In this study, the distribution frequencies of wild-type and heterozygous-type UGT1A1*28 were 69.8 and 30.2\%, respectively, in 86 patients in Guangxi Zhuang, with no homozygous-type case, which indicated that the homozygous mutation rate was further reduced as compared to the Asian Han ethnicity.

UGT1A1"6 is a unique UGT1A1 mutation type in Asian populations. The frequencies of $U G T 1 A 1^{*} 6$ homozygous mutant $\mathrm{A} / \mathrm{A}$ in Koreans and Japanese were reported to be 7 and $4 \%$, respectively, while the frequencies of $U G T 1 A 1 * 6 \mathrm{G} / \mathrm{G}, \mathrm{G} / \mathrm{A}$ and $\mathrm{A} / \mathrm{A}$ in Han Chinese were $66.9,29.3$ and $3.8 \%$, respectively [20]. This study revealed that the frequencies of wild-type, heterozygous-type and homozygous-type UGT1A1*6 in Guangxi Zhuang were 76.7, 20.9 and 2.3\%, respectively, which differed from the reported distribution frequencies of genetic polymorphisms in Europeans and Americans, wherein the mutation rate was slightly lower than that in Chinese Han and other Asians. However, this may be due to a small sample size. Equilibrium test of UGT1A1*28 and UGT1A1*6 allelic frequencies in this study revealed that the samples were in accordance with the Hardy-Weinberg equilibrium, derived from a larger and randomized marriage-balanced population, and was representative.

Table 9 Response to treatment and UGT1A1 status (\%)

\begin{tabular}{|c|c|c|c|c|c|c|}
\hline \multirow[t]{2}{*}{ Effect } & \multicolumn{2}{|c|}{ UGT1A $1 * 28$} & \multirow[t]{2}{*}{$P$} & \multicolumn{2}{|c|}{ UGT1A1*6 } & \multirow[t]{2}{*}{$P$} \\
\hline & $\begin{array}{l}\text { TA6/6 } \\
\text { Number } \\
(\%)\end{array}$ & $\begin{array}{l}\text { TA6/7 } \\
\text { Number } \\
(\%)\end{array}$ & & $\begin{array}{l}\mathrm{G} / \mathrm{G} \\
\text { Number } \\
(\%)\end{array}$ & $\begin{array}{l}\mathrm{G} / \mathrm{A}+\mathrm{A} / \mathrm{A} \\
\text { Number (\%) }\end{array}$ & \\
\hline$\overline{C R}$ & $0(0)$ & $2(7.7)$ & 0.729 & $1(1.5)$ & $1(5.0)$ & 0.745 \\
\hline$P R$ & $23(38.3)$ & $9(34.6)$ & & $26(39.4)$ & $8(40.0)$ & \\
\hline SD & $21(35.0)$ & $9(34.6)$ & & $22(33.3)$ & $6(30.0)$ & \\
\hline PD & $16(26.7)$ & $6(23.1)$ & & $17(25.8)$ & $5(25.0)$ & \\
\hline
\end{tabular}




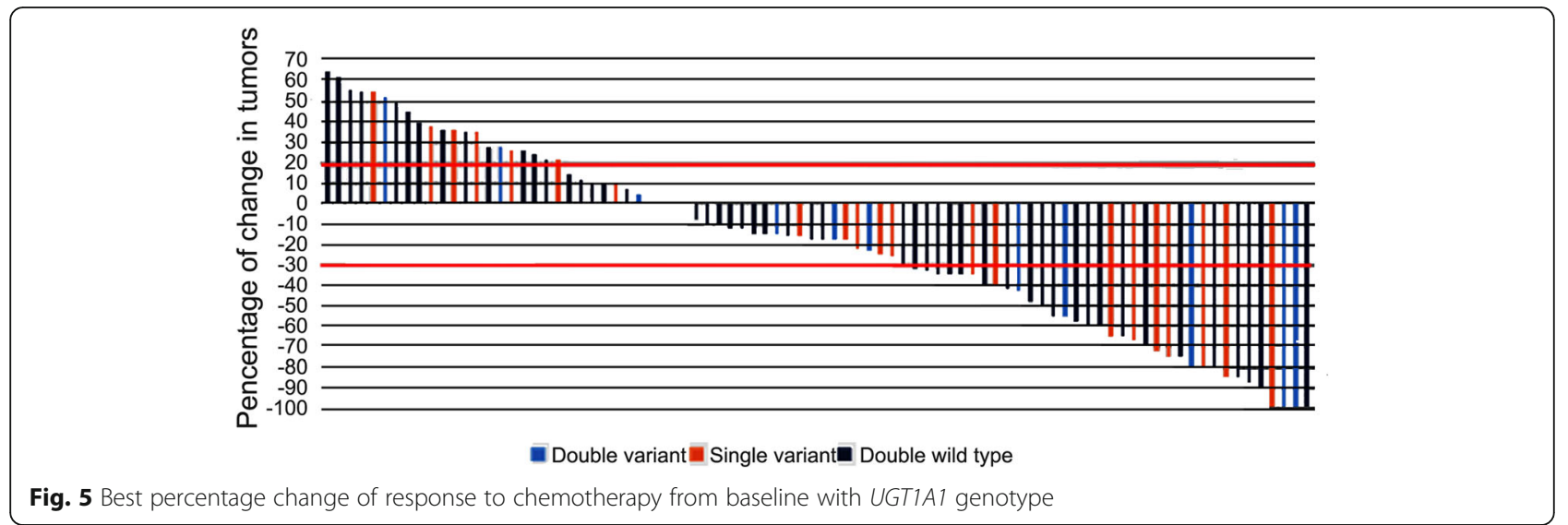

Clinical studies have shown that Caucasians with UGT1A1*28 gene mutants (TA6/7 and TA7/7) have a higher risk of severe granulocytopenia and diarrhea than those with wild-type UGT1A1*28 (TA6/6) after receiving irinotecan [21]. In our study, Guangxi Zhuang patients with UGT1A1*28 mutations showed a higher risk of 3 4 grade delayed-onset diarrhea as compared to those with wild-type UGT1A1*28 (30.8\% vs. $11.7 \%, p=0.044)$, but did not have a higher risk of 3 4 grade neutropenia (34.6\% vs. $15.0 \%, p=0.112$ ), which was consistent with other domestic reports [22]. Moreover, Guangxi Zhuang patients with $U G T 1 A 1 * 6$ mutations had a higher risk of 3 4 grade delayed-onset diarrhea after receiving irinotecan ( $45 \%$ vs. $9.1 \%, p=0.001)$, and an increased risk of $3 \sim 4$ grade neutropenia ( $40 \%$ vs. $15.2 \%, p=$ 0.017), which was consistent with numerous clinical studies in Japan [23-25]. The correlation between

Table 10 Response compared withUGT1A1wild-type、 singlepoint and double-point mutants (\%)

\begin{tabular}{|c|c|c|c|c|c|c|c|}
\hline Genotype & Total $n$ & $\begin{array}{l}\text { ORR } \\
\%(n)\end{array}$ & $x^{2}$ & P & $\begin{array}{l}\text { DCR } \\
\%(n)\end{array}$ & $x^{2}$ & $P$ \\
\hline UGT1A1*28 & & & 0.120 & 0.812 & & 0.123 & 0.794 \\
\hline $6 / 6$ & 60 & $38.3(23)$ & & & $73.3(44)$ & & \\
\hline $6 / 7$ & 26 & $42.3(11)$ & & & $76.9(20)$ & & \\
\hline UGT1A $1 * 6$ & & & 0.106 & 0.799 & & 0.005 & 1.000 \\
\hline $\mathrm{G} / \mathrm{G}$ & 66 & $40.9(27)$ & & & $74.2(49)$ & & \\
\hline $\mathrm{G} / \mathrm{A}+\mathrm{A} / \mathrm{A}$ & 20 & $45.0(9)$ & & & $75.0(15)$ & & \\
\hline $\begin{array}{l}\text { Numbers of } \\
\text { mutational } \\
\text { alleles }\end{array}$ & & & 0.069 & 1.000 & & 0.329 & 0.879 \\
\hline $\begin{array}{l}\text { Double single } \\
\text { type }\end{array}$ & 53 & $41.5(22)$ & & & $75.5(40)$ & & \\
\hline Single variant & 22 & 40.9(9) & & & $72.7(16)$ & & \\
\hline $\begin{array}{l}\text { Double } \\
\text { variant }\end{array}$ & 11 & $44.5(5)$ & & & $81.8(9)$ & & \\
\hline
\end{tabular}

UGT1A1 genotype and adverse reactions of irinotecan remains controversial. For the effect of UGT1A1* 28 mutant on delayed-onset diarrhea and $3 \sim 4$ grade granulocytopenia, only one adverse reaction was mentioned in some studies. For example, Miyata et al. only compared the risk of neutropenia, but not the risk of delayed-onset diarrhea [26]. Also, the predictive effects were refuted in some studies, but supported in other studies. Some studies supported the predictive effect on 3 4 grade neutropenia but refuted the risk of delayed-onset diarrhea [17], while others supported the occurrence of delayed-onset diarrhea but refuted the risk of 3 4 grade neutropenia [22]. In addition to the racial differences, we believe it is also related to the dose of irinotecan. In many studies, Caucasians were enrolled and a larger initial dose of irinotecan may have been selected, but the dose of irinotecan was not investigated. Previous studies revealed that UGT1A1*28 and UGT1A1*6 have a predictive effect on the adverse reactions of intermediate or high dose of irinotecan, but not on a low dose of irinotecan [27]. In this study, the homozygous and heterozygous mutations of UGT1A1 showed a predictive effect when the dose of irinotecan was reduced. For UGT1A1*28 and UGT1A1*6, the incidence of 3 4 grade neutropenia and 3 4 grade diarrhea significantly declined in both the dose reduction and non-reduction groups.

Table 11 Correlation between UGT1A1 genetic polymorphisms and irinotecan dose reduction in patients with CRC

\begin{tabular}{|c|c|c|c|c|c|c|}
\hline \multirow{2}{*}{$\begin{array}{l}\text { Irinotecan } \\
\text { dose } \\
\text { reduction }\end{array}$} & \multicolumn{2}{|c|}{ UGT1A1*28 } & \multirow[t]{2}{*}{$P$} & \multicolumn{2}{|l|}{ UGT1A1*6 } & \multirow[t]{2}{*}{$P$} \\
\hline & $\begin{array}{l}\text { TA6/6 } \\
\text { Number } \\
(\%)\end{array}$ & $\begin{array}{l}\text { TA6/7 + } \\
\text { TA7/7 } \\
\text { Number } \\
(\%)\end{array}$ & & $\begin{array}{l}\mathrm{G} / \mathrm{G} \\
\text { Number } \\
(\%)\end{array}$ & $\begin{array}{l}\text { G/A } \\
\text { Number } \\
(\%)\end{array}$ & \\
\hline Yes & $6(10.0)$ & $9(45.0)$ & 0.014 & 7 (10.6) & $8(40.0)$ & 0.007 \\
\hline No & $54(90.0)$ & $11(55.0)$ & & 59 (89.4) & $12(60.0)$ & \\
\hline
\end{tabular}




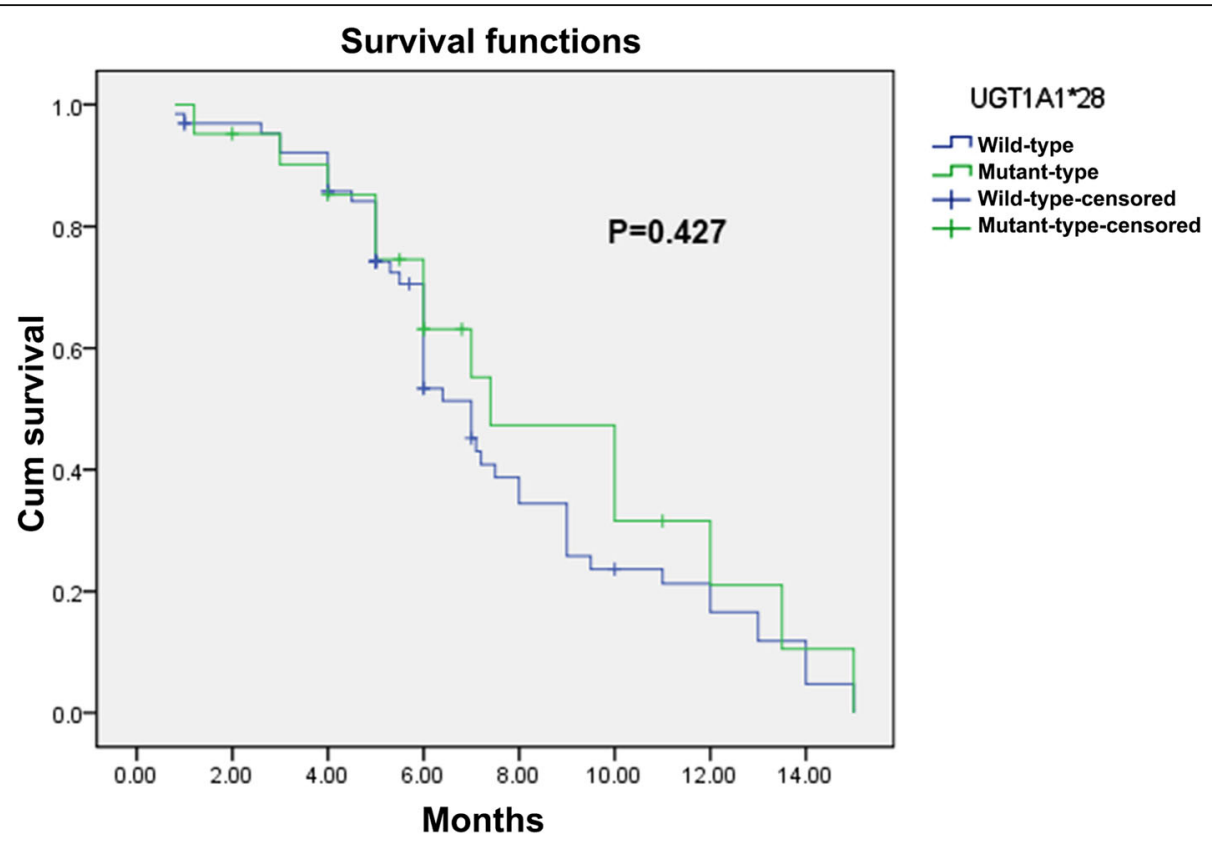

Fig. 6 Progression-Free Survival of patients with wild-type UGT1A1* 28 and mutant-type UGT1A1* 28

The correlation between UGT1A1 gene polymorphism and efficacy of irinotecan chemotherapy remains inconclusive. Toffoli et al. [28] believed that the efficacy was better in patients with mutant $U G T 1 A 1 * 28$ as compared to those with wild-type $U G T 1 A 1^{*} 28$. However, others believed that the efficacy was better in wild-type patients as compared to mutant patients [29], or the UGT1A1 gene polymorphism was not correlated with the efficacy [30]. The relationship between UGT1A1 gene polymorphism and adverse reactions of chemotherapy has

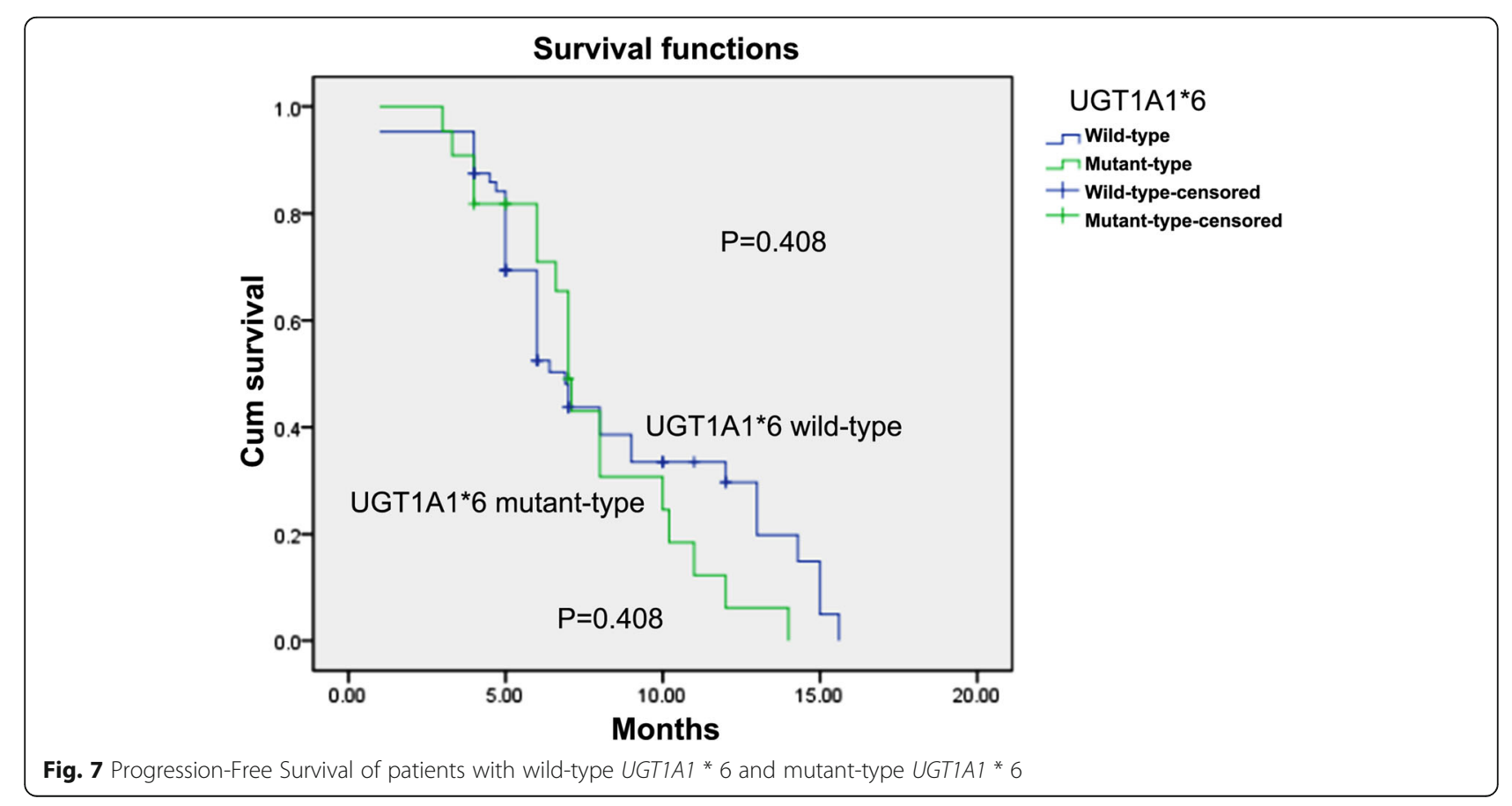


Table 12 Toxicity with irinotecan dose reduction and UGT1A1 status (\%)

\begin{tabular}{|c|c|c|c|c|}
\hline \multirow[t]{2}{*}{ Toxicity } & \multicolumn{2}{|l|}{ UGT1A1*28 } & \multicolumn{2}{|l|}{ UGT1A1*6 } \\
\hline & $\begin{array}{l}\text { Dose } \\
\text { reduction }\end{array}$ & $\begin{array}{l}\text { Non-dose } \\
\text { reduction }\end{array}$ & $\begin{array}{l}\text { Dose } \\
\text { reduction }\end{array}$ & $\begin{array}{l}\text { Non-dose } \\
\text { reduction }\end{array}$ \\
\hline \multicolumn{5}{|l|}{ Diarrhea } \\
\hline 0 grade & $6(40.0)$ & $47(66.2)$ & $8(53.3)$ & 45 (63.4) \\
\hline $1-2$ grade & $9(60.0)$ & 21 (29.6) & $6(40.0)$ & 24 (33.8) \\
\hline 3-4 grade & $0(0.0)$ & $3(4.2)$ & $1(6.7)$ & $2(2.8)$ \\
\hline \multicolumn{5}{|l|}{ Neutropenia } \\
\hline 0 grade & $9(60.0)$ & $45(63.4)$ & $9(60.0)$ & 48 (67.6) \\
\hline $1-2$ grade & $5(33.3)$ & 21 (29.6) & $4(26.7)$ & 21 (29.6) \\
\hline $3-4$ grade & $1(6.7)$ & $5(7.0)$ & $2(13.3)$ & $2(2.8)$ \\
\hline
\end{tabular}

been reported in several studies, while the efficacy of chemotherapy has been rarely studied. This study showed that the polymorphism of UGT1A1*28 and $U G T 1 A 1^{*} 6$ genes in Guangxi Zhuang patients with CRC was not significantly correlated with the RR and median PFS of irinotecan chemotherapy. Nevertheless, the correlation between UGT1A1 polymorphism and efficacy of irinotecan chemotherapy needs further verification with a large sample size study.

The above results may be affected by differences in population, drug dose, and a small sample size. Whether the gene polymorphism distribution and inter-individual variations in response to irinotecan in Chinese Zhuang are different from that in Han as well as European and American populations remains
Table 13 Comparison of short-term effects between the irinotecan dose reduction group and non-dose reduction group

\begin{tabular}{|c|c|c|c|c|c|c|}
\hline \multirow[t]{2}{*}{ Effect } & \multicolumn{2}{|c|}{ UGT1A1*28 } & \multirow[t]{2}{*}{$p$} & \multicolumn{2}{|l|}{ UGT1A1*6 } & \multirow[t]{2}{*}{$p$} \\
\hline & $\begin{array}{l}\text { Dose } \\
\text { reduction }\end{array}$ & $\begin{array}{l}\text { Non-dose } \\
\text { reduction }\end{array}$ & & $\begin{array}{l}\text { Dose } \\
\text { reduction }\end{array}$ & $\begin{array}{l}\text { Non-dose } \\
\text { reduction }\end{array}$ & \\
\hline$\overline{P R}$ & $2(13.3)$ & $11(15.5)$ & \multirow[t]{3}{*}{0.378} & $4(26.7)$ & $9(12.7)$ & \multirow[t]{3}{*}{0.388} \\
\hline SD & $9(60.0)$ & $29(40.8)$ & & $6(40.0)$ & $33(46.5)$ & \\
\hline PD & $4(26.7)$ & $31(43.7)$ & & $5(33.3)$ & $29(40.8)$ & \\
\hline
\end{tabular}

unknown. The sample size should be increased and the follow-up survival should be analyzed based on the gene distribution characteristics of Chinese and combined with the drug dose, in order to achieve the goal of individualization.

\section{Conclusions}

The frequency of gene mutation differs among various ethnic groups due to different genetic backgrounds. In our study, we found the distribution frequencies of wild-type, heterozygous-type and homozygous-type UGT1A1 in Guangxi Zhuang patients of metastatic colorectal cancer differed from the reported distribution frequencies of genetic polymorphisms in European patients people and Chinese Han patients. The UGT1A1 gene polymorphism with irinotecan chemotherapy-associated diarrhea and neutropenia were closely related. Guangxi Zhuang patients of metastatic colorectal cancer with UGT1A1*28 mutations showed a higher risk of 3 4 grade diarrhea as compared to those with wild-type

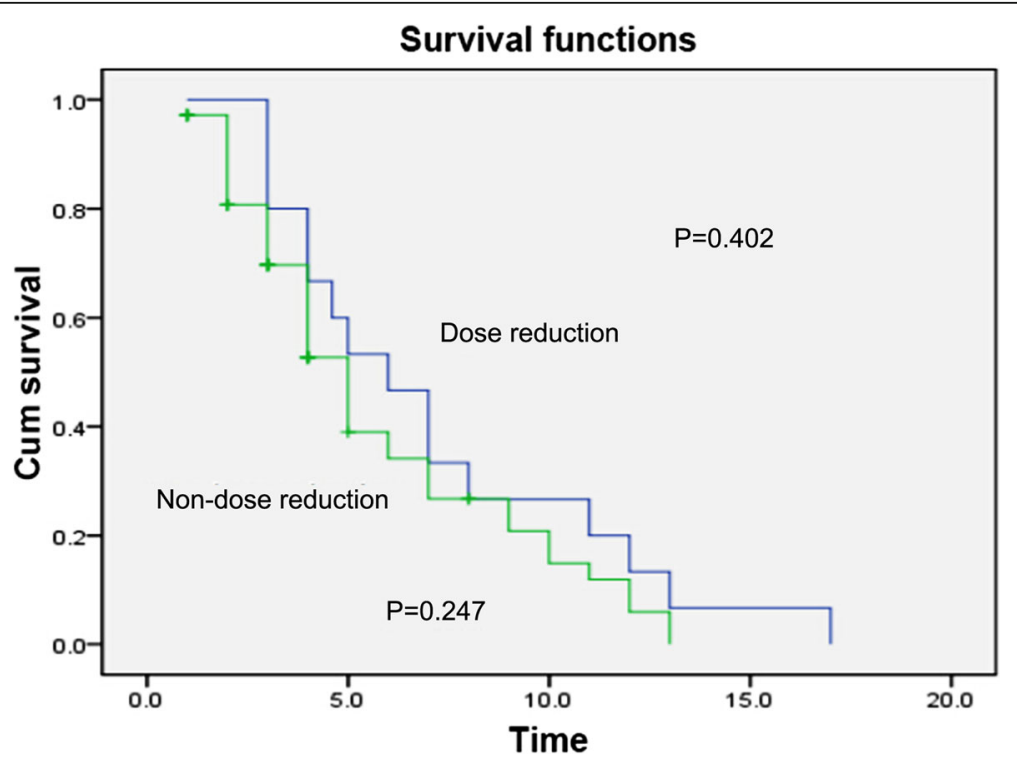

Fig. 8 Comparison of long-term effects between the dose reduction group and non-reduction group in patients with UGT1A1*28 gene 


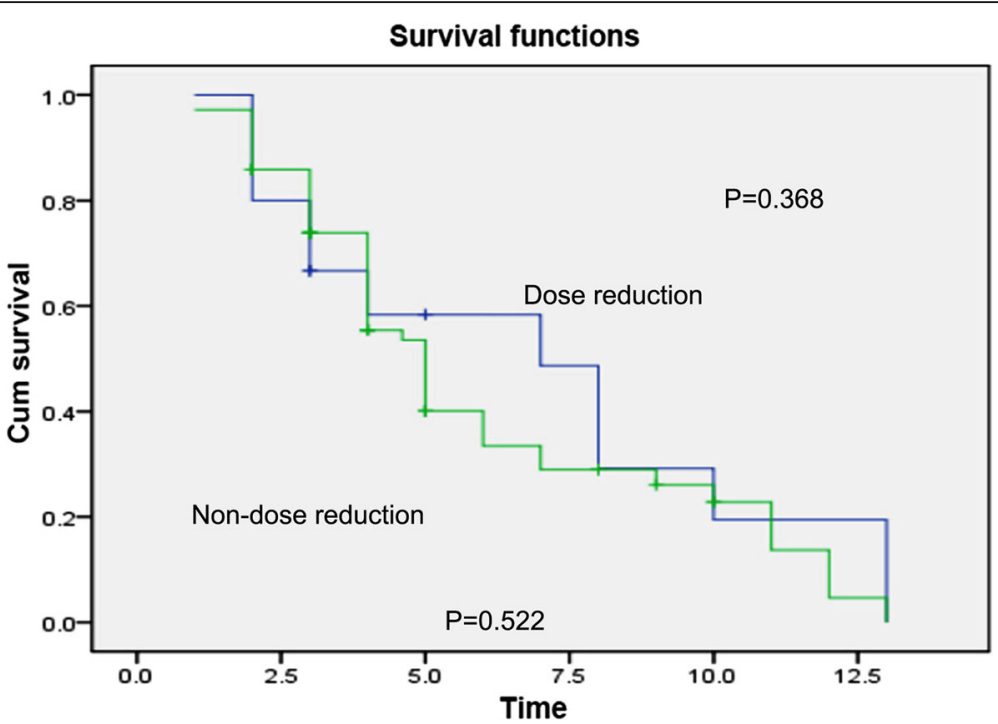

Fig. 9 Comparison of long-term effect between the dose reduction group and non-reduction group in patients with UGT1A1*6 gene

UGT1A1*28 which did not increase the risk of grade 3 4 neutropenia. Moreover, Guangxi Zhuang patients with UGT1A1*6 mutations had a higher risk of $3 \sim 4$ grade diarrhea and neutropenia those with wild-type. After chemotherapy with FOLFIRI, there was no significant difference in response rate and the median progression-free survival between the wild-type, mutant treatment of UGT1A1 *28 and UGT1A1 *6. The above results may be affected by differences in population, or drug dose. The follow-up survival should be analyzed based on the gene distribution characteristics of Chinese and combined with the drug dose, in order to achieve the goal of individualization.

\section{Abbreviations}

CE: Carboxylesterase; CRC: Colorectal cancer; HWE: Hardy-Weinberg equilibrium; mCRC: Metastatic colorectal cancer; mPFS: Median progressionfree survival; RR: Response rate; UGT1A1: Uridine diphosphate glucuronosyl transferase $1 \mathrm{~A} 1$

\section{Acknowledgements}

Not Applicable.

\section{Authors' contributions}

SC, LH, CF, QM and MW contributed to the study design, literature research, interpretation of findings and writing of the manuscript. YS and ZL contributed to the follow-up, data collection and analyses. GL provided suggestion of statistics. XJ, CG and HH contributed to critical review of data analyses and critical edit of the manuscript. All authors reviewed and approved the final manuscript.

\section{Funding}

This study was supported by the National Natural Science Foundation of China (NSFC:81260340) and Guangxi Natural Science Foundation (2013GXNSFAA019263). The sponsor had no role in:study design;collection,analyses,or interpretation of data;manuscript writing;or in the decision to publish the results.

\section{Availability of data and materials}

The data sets used and/or analyzed during the current study are available from the corresponding author on reasonable request.

\section{Ethics approval and consent to participate}

This study was approval by the Ethics Committee of Guangxi Medical University and the Forth Affiliated Hospital of Guangxi Medical University, written informed consent was obtained from each patient.

\section{Consent for publication}

Not applicable.

\section{Competing interests}

The authors declare that they have no competing interests.

\section{Author details}

'Department of Oncology, the Forth Affiliated Hospital of Guangxi Medical University, No.1 liushi Road, Liuzhou 545005, Guangxi, China. ${ }^{2}$ Department of Chemotherapy, Liuzhou Cancer Hospital, Liuzhou 545006, Guangxi, China. ${ }^{3}$ Department of Oncology, The Liuzhou Railway Affiliated Hospital of Guangxi Medical University, Liuzhou 545007, Guangxi, China. ${ }^{4}$ Department of Oncology, The Yulin First People's Hospital, Yulin 537000, Guangxi, China. ${ }^{5}$ Department of Gastroenterological Surgery, The Fourth Affiliated Hospital of Guangxi Medical University, Liuzhou 545005, Guangxi, China. ${ }^{6} \mathrm{Clinical}$ Pharmacology Center, The Third Xiangya Hospital of Central South University, Changsha 410013, Hunan, China.

Received: 1 January 2020 Accepted: 19 March 2020

Published online: 07 April 2020

\section{References}

1. Torre LA, Bray F, Siegel RL, et al. Global cancer statistics, 2012. CA Cancer J Clin. 2015;65:87-108

2. Jakobsen A, Andersen F, Fischer $A$, et al. Neoadjuvant chemotherapy in locally advanced colon cancer. A phase II trial. Acta Oncol. 2015;54:1747-53.

3. Huo YR, Huang Y, Liauw W, Zhao J, Morris DL. Prognostic value of carcinoembryonic antigen (CEA), AFP, CA19-9 and CA125 for patients with colorectal cancer with peritoneal Carcinomatosis treated by Cytoreductive surgery and intraperitoneal chemotherapy. Anticancer Res. 2016;36:1041-9.

4. Arredondo J, González I, Baixauli J, et al. Tumor response assessment in locally advanced colon cancer after neoadjuvant chemotherapy. J Gastrointest Oncol. 2014;5:104-11. 
5. Suenaga M, Mizunuma N, Matsusaka S, et al. A phase $1 / / \mid$ study of biweekly capecitabine and irinotecan plus bevacizumab as second-line chemotherapy in patients with metastatic colorectal cancer. Drug Des Devel Ther. 2015:9:1653-62.

6. Chen Z, Su D, Ai L, et al. UGT1A1 sequence variants associated with risk of adult hyperbilirubinemia: a quantitative analysis. Gene. 2014;552:32-8.

7. Yan W, Wang YW, Yang FF, et al. Differences in frequencies of UGT1A19, 1A, and $1 \mathrm{~A} 1$ genetic polymorphisms in Chinese Tibetan versus Han Chinese populations. Genet Mol Res. 2013;12:6454-61.

8. Kim JH, Min SJ, Jang HJ, et al. Comparison of RECIST 1.0 and RECIST 1.1 in patients with metastatic cancer: a pooled analysis. J Cancer. 2015;6:387-93.

9. Trotti A. The need for adverse effects reporting standards in oncology clinical trials. J Clin Oncol. 2004;22:19-22.

10. Ottaiano A, Nasti G, Cassata A, et al. FOLFOXIRI in metastatic colorectal cancer: a criticism from its native land. Cancer Lett. 2017;408:71-2.

11. Leal F, Ferreira FP. FOLFOXIRI regimen for metastatic colorectal cancer: a systematic review and meta-analysis. Clin Colorectal Cancer. 2017. https:// doi.org/10.1016/j.clcc.2017.03.012

12. Wulaningsih W, Wardhana A, Watkins J, Yoshuantari N, Repana D, Van Hemelrijck M. Irinotecan chemotherapy combined with fluoropyrimidines versus irinotecan alone for overall survival and progression-free survival in patients with advanced and/or metastatic colorectal cancer. Cochrane Database Syst Rev. 2016;2:CD008593.

13. Liu D, Li J, Gao J, Li Y, Yang R, Shen L. Examination of multiple UGT1A and DPYD polymorphisms has limited ability to predict the toxicity and efficacy of metastatic colorectal cancer treated with irinotecan-based chemotherapy: a retrospective analysis. BMC Cancer. 2017;17:437.

14. Kaniwa N, Kurose $\mathrm{K}$, Jinno $\mathrm{H}$, et al. Racial variability in haplotype frequencies of UGT1A1 and glucuronidation activity of a novel single nucleotide polymorphism 686C> T (P229L) found in an African-American. Drug Metab Dispos. 2005;33:458-65.

15. Marcuello E, Altés A, Menoyo A, et al. UGT1A1 gene variations and irinotecan treatment in patients with metastatic colorectal cancer. $\mathrm{Br} J$ Cancer. 2004;91:678-82.

16. Hirose K, Kozu C, Yamashita K, et al. Correlation between plasma concentration ratios of $\mathrm{SN}-38$ glucuronide and $\mathrm{SN}-38$ and neutropenia induction in patients with colorectal cancer and wild-type UGT1A1 gene. Oncol Lett. 2012;3:694-8.

17. Gao J, Zhou J, Li Y, et al. UGT1A1 6/28 polymorphisms could predict irinotecan-induced severe neutropenia not diarrhea in Chinese colorectal cancer patients. Med Oncol. 2013;30:604

18. Nakamura $Y$, Soda H, Oka M, et al. Randomized phase II trial of irinotecan with paclitaxel or gemcitabine for non-small cell lung cancer: association of UGT1A $1^{*} 6$ and UGT1A1*27 with severe neutropenia. J Thorac Oncol. 2011;6: $121-7$.

19. Etienne-Grimaldi MC, Boyer JC, Thomas F, et al. UGT1A1 genotype and irinotecan therapy: general review and implementation in routine practice. Fundam Clin Pharmacol. 2015;29:219-37.

20. Zhang A, Xing Q, Qin S, et al. Intra-ethnic differences in genetic variants of the UGT-glucuronosyltransferase $1 \mathrm{~A} 1 \mathrm{gene}$ in Chinese populations. Pharmacogenomics J. 2007;7:333-8

21. Martinez-Balibrea E, Abad A, Martínez-Cardús A, et al. UGT1A and TYMS genetic variants predict toxicity and response of colorectal cancer patients treated with first-line irinotecan and fluorouracil combination therapy. $\mathrm{Br} J$ Cancer. 2010;103:581-9.

22. Zhou CF, Ma T, Su Y, et al. UGT1A1 gene polymorphisms and the toxicities of FOLFIRI in Chinese Han patients with gastrointestinal cancer. Anti Cancer Agents Med Chem. 2013;13:235-41.

23. Onoue $M$, Terada $T$, Kobayashi $M$, et al. UGT1A1*6 polymorphism is most predictive of severe neutropenia induced by irinotecan in Japanese cancer patients. Int J Clin Oncol. 2009;14:136-42.

24. Takano M, Kato M, Yoshikawa T, et al. Clinical significance of UDPglucuronosyltransferase $1 \mathrm{~A} 1 * 6$ for toxicities of combination chemotherapy with irinotecan and cisplatin in gynecologic cancers: a prospective multi-institutional study. Oncology. 2009;76:315-21.

25. Hu ZY, Yu Q, Pei Q. Dose-dependent association between UGT1A1*28 genotype and irinotecan-induced neutropenia: low doses also increase risk. Clin Cancer Res. 2010;16:3832-42.

26. Miyata $Y$, Touyama T, Kusumi T, et al. Erratum to: UDPglucuronosyltransferase $1 \mathrm{~A} 1{ }^{*} 6$ and ${ }^{*} 28$ polymorphisms as indicators of initial dose level of irinotecan to reduce risk of neutropenia in patients receiving FOLFIRI for colorectal cancer. Int J Clin Oncol. 2016;21:704.

27. Moriya H, Saito K, Helsby N, et al. Association between the low-dose irinotecan regimen-induced occurrence of grade 4 neutropenia and genetic variants of UGT1A1 in patients with gynecological cancers. Oncol Lett. 2014; 7:2035-40.

28. Toffoli G, Cecchin E, Corona G, et al. The role of UGT1A1*28 polymorphism in the pharmacodynamics and pharmacokinetics of irinotecan in patients with metastatic colorectal cancer. J Clin Oncol. 2006:24:3061-8.

29. Shulman K, Cohen I, Barnett-Griness O, et al. Clinical implications of UGT1A1*28 genotype testing in colorectal cancer patients. Cancer. 2011;117: 3156-62.

30. Sugiyama T, Hirose T, Kusumoto $\mathrm{S}$, et al. The UGT1A1*28 genotype and the toxicity of low-dose irinotecan in patients with advanced lung cancer Oncol Res. 2010;18:337-42

\section{Publisher's Note}

Springer Nature remains neutral with regard to jurisdictional claims in published maps and institutional affiliations.

Ready to submit your research? Choose BMC and benefit from:

- fast, convenient online submission

- thorough peer review by experienced researchers in your field

- rapid publication on acceptance

- support for research data, including large and complex data types

- gold Open Access which fosters wider collaboration and increased citations

- maximum visibility for your research: over $100 \mathrm{M}$ website views per year

At $\mathrm{BMC}$, research is always in progress.

Learn more biomedcentral.com/submissions 